\title{
Report of a rare case of sepsis caused by Bacillus pumilus in an immunocompetent child with the involvement of soft tissues cellulitis
}

\author{
Libera Clemente, ${ }^{1}$ Dana Dragovic, ${ }^{2}$ Cristina Milocco, ${ }^{2}$ Francesco Fontana ${ }^{1}$ \\ ${ }^{1}$ Laboratory of Clinical Chemistry and Microbiological Analysis AAS2, and ${ }^{2}$ Pediatric Ward AAS2 \\ Bassa Friulana-Isontina General Hospital, S. Polo Monfalcone (GO), Italy
}

\section{Summary}

Bacillus pumilus is an environmental contaminant, rarely associated with human diseases. In this report we describe a case of a severe sepsis caused by $B$. pumilus in a 7-year-old healthy child. The microorganism has been isolated from two blood cultures and has been identified using both biochemical tests and mass spectrometry. The patient fully recovered after an ampicillin treatment.

\section{Introduction}

The genus Bacillus includes different species, but apart bacteremias caused by Bacillus anthracis and Bacillus cereus which affect principally immunocompromised patients and/or with hematological malignancies $(10,11,13)$, other species rarely cause infections (4). The major clinical syndromes caused by Bacillus spp. other than $B$. anthracis and $B$. cereus are the following.

Correspondence: Libera Clemente, Laboratory of Clinical Chemistry and Microbiological Analysis AAS2, Bassa Friulana-Isontina, Via Galvani 1, 34074 Monfalcone (G0), Italy.

Tel.:+39.340.3620303.

E-mail: liberaclemente@hotmail.com

Key words: B. pumilus, sepsis, contamination, true pathogen.

Contributions: the authors contributed equally.

Conflict of interest: the authors declare no potential conflict of interest.

Received for publication: 15 September 2016.

Revision received: 13 October 2016.

Accepted for publication: 15 October 2016.

(C) Copyright L. Clemente et al., 2016

Licensee PAGEPress, Italy

Microbiologia Medica 2016; 31:6289

doi:10.4081/mm.2016.6289

This article is distributed under the terms of the Creative Commons Attribution Noncommercial License (by-nc 4.0) which permits any noncommercial use, distribution, and reproduction in any medium, provided the original author(s) and source are credited.
B. circulans and B. licheniformis: meningitis, cerebrospinal fluid shunt infections, endocarditis, wound infections, endophthalmitis, bacteremia, catheter-related sepsis, food poisoning, central nervous system infections after surgery or trauma.

B. pumilus and B. megaterium: meningitis (5), bacteremias (1, 7, 8), soft tissue infections (12), catheter-related sepsis and endocarditis $(2,9)$, septic arthritis (14).

B. sphaericus and B subtilis: peritonitis, otitis, mastoiditis, bacteremia, pneumonia, endocarditis, shunt infections, food poisoning.

Bacillus pumilus is a Gram-positive, aerobic, spore-forming microrganism usually found in the soil as a commensal and more commonly isolated in cultures as contaminant. The laboratory isolation of $B$. pumilus needs to be carefully evaluated and an immediate alert to the clinician often creates a therapeutical dilemma, even in high risk patients (15). We report a severe sepsis' case caused by B. pumilus in a 7 year old child.

\section{Case Report}

A seven year old child has been brought to the pediatric ward of the Monfalcone's General Hospital because of pain in the third rear-medial portion of the right thigh which started 2-3 days before, a worsening limp and difficulty in extending the right knee, which didn't appear swollen, hot, hyperemic or humid. In the history there was no evidence of trauma, wound, bite or any kind of lesion. The child appeared in good clinical conditions with a temperature of $37.6^{\circ} \mathrm{C}$. The right thigh was very painful at compression in particular the first rear medial portion and the right popliteus cavity. The other joints (ankles, hip, wrists, elbows) were symptom and sign free.

The laboratory exams showed signs of mild inflammation, with a white blood cell count of $17.300 / \mathrm{mmc}$ and a CRP of $3.92 \mathrm{mg} / \mathrm{dL}$. The patient was hospitalized with the suspect of osteomyelitis of the right leg; a nuclear magnetic resonance (RMN) was performed but didn't show evident alterations of the right osteoarticular apparatus; in the popliteus cavity there was a soft tissue's swollen area $15 \times 20 \mathrm{~mm}$ compressing the popliteus vein. A right knee ultrasonography was carried out, which showed the presence of the soft tissue's swelling $15 \times 20 \mathrm{~mm}$ in size around the vessels in the knee cavity.

A blood culture test was carried out during the febrile peak and the treatment started immediately with oxacillin $900 \mathrm{mg} \times 3 \mathrm{IV}$.

The blood culture became positive after an overnight incubation at $35^{\circ} \mathrm{C}$ (BacT/ALERT, PF pediatric FAN; bioMérieux) and the microscopical examination of the Gram slide showed Gram positive rods. The species was identified in a presumptive manner as $B$. pumilus with VITEK $^{\circledR} 2$ BCL (BCL TEST KIT - bioMérieux) and confirmed finally by means of mass spectrometry MALDI-TOF (VITEK ${ }^{\circledR}$ MS - bioMérieux) with $99,9 \%$ confidence. The antimicrobial susceptibility test was per- 
Table 1. Antimicrobial susceptibility test.

\begin{tabular}{|c|c|c|c|c|c|}
\hline & & $(\mu g / 1$ & & Result & \\
\hline & S & I & $\mathbf{R}$ & CLSI M45-A3 2015 & MIC ( $\mu g / m L)$ \\
\hline Cefotaxime & $\leq 8$ & $16-32$ & $\geq 64$ & $\mathrm{R}$ & 32 \\
\hline Ceftriaxone & $\leq 8$ & $16-32$ & $\leq \geq 64$ & $\mathrm{R}$ & 32 \\
\hline Clindamycin & $\leq 0.5$ & $1-2$ & $\geq 4$ & $\mathrm{R}$ & 6 \\
\hline Erythromycin & $\leq 0.5$ & $1-4$ & $\geq 8$ & $\mathrm{R}$ & 8 \\
\hline Imipenem & $\leq 4$ & 8 & $\geq 16$ & S & 0.094 \\
\hline Levofloxacin & $\leq 2$ & 4 & $\geq 8$ & S & 0.50 \\
\hline Penicillin G & $\leq 0.12$ & - & $\geq 0.25$ & S & 0.094 \\
\hline Ampicillin & - & - & - & - & 0.094 \\
\hline Oxacillin & - & - & - & - & 2 \\
\hline Vancomycin & $\leq 4$ & - & - & S & 0.125 \\
\hline
\end{tabular}

formed using Etest gradient diffusion method (Etest; bioMérieux). Because there are not EUCAST interpretative criteria for Bacillus spp. other than B. anthracis, we applied those described in the CLSI M45-A3 2015 document (3-5) (Table 1). Even though the indications are against it, oxacillin has been tested to verify the therapy efficacy.

Microbiological and radiological results oriented the clinicians to speculate a Bacillus spp. sustained sepsis of soft tissues of the right leg. On the base of the microbial susceptibility test, ampicillin was added on the third day and so the dual therapy was carried out for other six days: i) ampicillin $100 \mathrm{mg} / \mathrm{kg} / \mathrm{die}(600 \mathrm{mg} \times 3 \mathrm{IV}$ ); ii) oxacillin 150 $\mathrm{mg} / \mathrm{kg} / \mathrm{die}(900 \mathrm{mg} \times 3 \mathrm{IV})$.

After the six days dual therapy, oxacillin was suspended and the boy remained on ampicillin $(600 \mathrm{mg} \times 3 \mathrm{IV})$ for other 8 days.

\section{Results}

The clinical evolution was benign, the patient had definitely a normal temperature after 4 days of dual intravenous therapy, a complete normalization of blood levels (GB 6.800/mmc, PCR $0.09 \mathrm{mg} / \mathrm{dL}$ ) and an ultrasonography of the right thigh that didn't show any residual injury. All the symptoms recovered after 8 days of therapy and when he was discharged from the hospital he was completely symptom free after 14 days of antibiotic therapy.

\section{Discussion and Conclusions}

There are very few reported cases of neonatal or pediatric sepsis caused by Bacillus spp. other than B. anthracis and B. cereus $(1,6,8)$, even though the neonatal population is particularly susceptible to environmental bacteria due to functional, cellular and molecular lacking of humoral and cellular immunity (13).

The low number of cases could be due to the fact that many laboratories aren't able to identify accurately these microorganisms to the species level and probably consider them as contaminants without really discussing the item with clinicians. Previous studies have shown that some Bacillus spp. should be treated as pathogens especially in newborns or in immunocompromized patients or even when isolated repeatedly in blood cultures $(1,7,8,10,11)$. In our case report in fact the microorganism was isolated from two blood cultures but all other culture essays were negative, so it becomes very important to talk with clinicians in order to interpret correctly the laboratory results and clinical features and to distinguish a real infection from a simple contamination.

\section{References:}

1. Adler A, Gottesman G, Dolfin T, et al. Bacillus species sepsis in the neonatal intensive care unit. J Infect 2005;51:390-5.

2. Bentur HN, Dalzell AM, Riordan FAI. Central venous catheter infection with Bacillus pumilus in an immunocompetent child: a case report. Ann Clin Microbiol Antimicrob 2007;6:12.

3. CLSI M100S. Performance Standards for Antimicrobial. Susceptibility Testing. Wayne: Clinical and Laboratory Standards Institute; 2016.

4. CLSI M45-A3. Methods for Antimicrobial dilution and disk susceptibility testing of infrequently isolated or fastidious bacteria. 3rd ed. Wayne: Clinical and Laboratory Standards Institute; 2015.

5. EUCAST. Clinical breakpoints: bacteria. (v. 6.0) 2016. Available from: http://www.eucast.org/clinical_breakpoints/

6. Farhat H, Chachaty E, Antoun S, et al. Two cases of Bacillus infection and immunodepression. Med Mal Infect 2008.38:612-4.

7. Kimouli M, Vrioni G, Papadopoulou M, et al. Two cases of severe sepsis caused by Bacillus pumilus in neonatal infants. J Med Microbiol 2012;61:596-9.

8. Goldstein JA, Beardslee MA, Xu H, et al. Infective endocarditis resulting from CardioSEAL closure of a patent foramen ovale. Catheter Cardiovasc Interv 2002;55:217-22.

9. Ozkocaman V, Ozcelik T, Ali R, et al. Bacillus spp. among hospitalized patients with haematological malignancies: clinical features, epidemics and outcomes. J Hosp Infect 2006;64:169-76.

10. Patrick C, Langston C, Baker CJ. Bacillus species infections in neonates. Rev Infect Dis 1989;11:612-5.

11. Tena D. Martinez-Torres JA, Perez-Pomata MT, et al. Cutaneous infection due to Bacillus pumilus: report of 3 cases. Clin Infect Dis 2007;44:e40-2.

12. Schelonka RL, Infante AJ. Neonatal immunology. Semin Perinatol 1998;22:2-14.

13. Shivamurthy VM, Gantt S, Reilly C, et al. Bacillus pumilus septic arthritis in a healthy child. Can J Infect Dis Med Microbiol 2016;2016:3265037.

14. Weber DJ, Saviteer SM, Rutala WA, Thomann CA. Clinical significance of Bacillus species isolated from blood cultures. South Med J 1989;82:705-9. 